\title{
Gene expression patterns and differential input into curli fimbriae regulation of all GGDEF/EAL domain proteins in Escherichia coli
}

\author{
Nicole Sommerfeldt, Alexandra Possling, Gisela Becker, \\ Christina Pesavento, Natalia Tschowri and Regine Hengge \\ Institut für Biologie - Mikrobiologie, Freie Universität Berlin, 14195 Berlin, Germany
}

Correspondence

Regine Hengge

Rhenggea@zedat.fu-berlin.de

Received 12 September 2008 Revised 16 December 2008 Accepted 18 December 2008

\begin{abstract}
Switching from the motile planktonic bacterial lifestyle to a biofilm existence is stimulated by the signalling molecule bis-(3'-5')-cyclic-diguanosine monophosphate (cyclic-di-GMP), which is antagonistically controlled by diguanylate cyclases (DGCs; characterized by GGDEF domains) and specific phosphodiesterases (PDEs; mostly featuring EAL domains). Here, we present the expression patterns of all 28 genes that encode GGDEF/EAL domain proteins in Escherichia coli $\mathrm{K}-12$. Twenty-one genes are expressed in Luria-Bertani medium, with 15 being under $\sigma^{\mathrm{S}}$ control. While a small subset of GGDEF/EAL proteins ( $\mathrm{YeaJ}$ and $\mathrm{YhjH}$ ) is dominant and modulates motility in post-exponentially growing cells, a diverse battery of GGDEF/EAL proteins is deployed during entry into stationary phase, especially in cells grown at reduced temperature $\left(28{ }^{\circ} \mathrm{C}\right)$. This suggests that multiple signal input into cyclic-di-GMP control is particularly important in growthrestricted cells in an extra-host environment. Six GGDEF/EAL genes differentially control the expression of adhesive curli fimbriae. Besides the previously described $y d a M, y c i R, y e g E$ and $y$ hiH genes, these are $y h d A(\operatorname{csr} D)$, which stimulates the expression of the DGC YdaM and the major curli regulator $\mathrm{CsgD}$, and yeaP, which contributes to expression of the curli structural operon csgBAC. Finally, we discuss why other GGDEF/EAL domain-encoding genes, despite being expressed, do not influence motility and/or curli formation.
\end{abstract}

\section{INTRODUCTION}

Bacteria can switch between a single-cell planktonic and motile lifestyle and a sessile multicellular state, i.e. a biofilm existence (Beloin et al., 2008). The ubiquitous bacterial second messenger bis- $\left(3^{\prime}-5^{\prime}\right)$-cyclic-diguanosine monophosphate (c-di-GMP) is a key regulatory factor that interferes with motility and stimulates adhesion and biofilm matrix production (for recent comprehensive reviews, see Jenal \& Malone, 2006; Römling et al., 2005; Ryan et al., 2006a; Tamayo et al., 2007; Wolfe \& Visick, 2008). Cellular c-di-GMP levels are controlled by antagonistically acting diguanylate cyclases (DGCs) and phosphodiesterases (PDEs). DGC activity in these enzymes is provided by GGDEF domains (Hickman et al., 2005; Paul et al., 2004; Ryjenkov et al., 2005), whereas PDE activity resides in EAL or HD-GYP domains (Chang et al., 2001;

Abbreviations: c-di-GMP, bis-(3'-5')-cyclic-diguanosine monophosphate; DGC, diguanylate cyclase; PDE, phosphodiesterase; RNAP, RNA polymerase.

Two supplementary tables, listing designations of homologous GGDEF/ EAL genes in Escherichia coli and Salmonella enterica (serovar Typhimurium), and oligonucleotide primers used, are available with the online version of this paper.
Christen et al., 2005; Ryan et al., 2006b; Schmidt et al., 2005; Tamayo et al., 2005). Active DGCs are characterized by an intact GGDEF motif that represents the active centre of the enzyme (called the A-site) and usually also carry an I-site, i.e. a secondary and inhibitory binding site for c-diGMP (Christen et al., 2005; Malone et al., 2007). Also, in EAL domains with PDE activity, a number of functionally important amino acids are highly conserved (Rao et al., 2008; Schmidt et al., 2005). Notably, many species also contain GGDEF/EAL domain proteins, in which these signatures are degenerate, and which therefore cannot act as DGCs or PDEs, but nevertheless generate phenotypes (Rao et al., 2008; Suzuki et al., 2006). GGDEF and EAL domains can occur alone or in combination in single polypeptides. The majority of these proteins also carry Nterminal sensory-input domains, which can control the activities of the GGDEF and/or EAL domains. C-di-GMP is bound by specific effector components, which can be proteins belonging to different families (Amikam \& Galperin, 2006; Benach et al., 2007; Christen et al., 2007; Hickman \& Harwood, 2008; Lee et al., 2007; Merighi et al., 2007; Ryjenkov et al., 2006) or RNA molecules acting as riboswitches (Sudarsan et al., 2008). These effectors control various target processes, including transcription initiation, 
enzyme activity and flagellar motor function (see reviews cited above).

While this overall mechanism of c-di-GMP control and action seems straightforward, current knowledge is rather fragmentary when it comes to the precise molecular details. Moreover, there is a striking multiplicity of GGDEF/EAL proteins in single species. In particular, proteobacteria often have several dozen such proteins. This immediately raises questions: can different GGDEF/EAL proteins act independently from one other and thereby affect different targets, or do all these proteins control a common cellular pool of diffusible c-diGMP and therefore a common set of targets? How is specificity of signalling achieved, i.e. potential crosstalk avoided, with so many proteins that make and break c-diGMP? Is there differential expression of genes encoding GGDEF/EAL domain proteins? Also, in order to identify the output functions of distinct GGDEF/EAL domain proteins, a knowledge of their conditions of expression is essential.

Here, we present the first systematic study, to our knowledge, of the expression of all genes encoding GGDEF/EAL domain proteins in a bacterial species. Depending on the strain, Escherichia coli K-12 has 28 or 29 such genes, i.e. a number that can still be handled in toto (in terms of making reporter fusions, mutations and functional assays for each of them in parallel). Moreover, $E$. coli exhibits a growth-phase-dependent lifestyle switch: during the post-exponential phase of the growth cycle (in complex medium), cells express flagella and become highly motile. Yet later, during entry into stationary phase, motility is downregulated (Adler \& Templeton, 1967; Amsler et al., 1993; Pesavento et al., 2008) and the expression of adhesive curli fimbriae is induced, which results in autoaggregation and adhesion to surfaces, an important early step in biofilm formation (Olsén et al., 1989; Pesavento et al., 2008; Weber et al., 2006). Both in E. coli and its close relative Salmonella, curli expression is known to be controlled by the general stress response and stationary phase sigma factor $\sigma^{\mathrm{S}}$ (RpoS) and by c-di-GMP (Kader et al., 2006; Pesavento et al., 2008; Römling et al., 1998; Simm et al., 2007; Weber et al., 2006). Here, we show highly differential expression of all genes encoding GGDEF/EAL domain proteins in E. coli as a function of parameters relevant for switching from motility to curlimediated adhesion, i.e. growth phase, temperature and growth on liquid or solid medium. We also demonstrate that the majority of expressed GGDEF/EAL domainencoding genes in E. coli are under the control of $\sigma^{\mathrm{S}}$, and provide evidence that six GGDEF/EAL genes differentially affect curli expression, whereas several others do not have such an influence, despite clear expression.

\section{METHODS}

Bacterial strains and growth conditions. All strains used in this study are derivatives of the E. coli K-12 strain W3110 (Hayashi et al., 2006) and also carry a $\Delta$ lac deletion. Mutations were transferred by P1 transduction (Miller, 1972). The following deletion-insertion muta- tions have been described previously: rpoS359::Tn10 (Lange \& Hengge-Aronis, 1991); yaiC:: kan, ydaM: :cat, yciR:: kan, yedQ: : cat, $y d d V:: \operatorname{Tn} 5, m l r A:: k a n, \operatorname{csg} D::$ cat (Weber et al., 2006); yegE::kan, yeaJ:: kan, yhjH:: cat (Pesavento et al., 2008). All other mutations are deletion-insertion mutations generated by one-step inactivation according to Datsenko \& Wanner (2000), using the primers listed in Supplementary Table S1 and pKD3 (cat cassette), pKD4 or pKD13 (kan cassettes) for the PCRs. In cases in which insertions could have a polar effect on downstream genes (for operon structures of certain genes encoding GGDEF/EAL proteins, see below) or insertions in multiple genes had to be combined, non-polar in-frame deletion mutations were also obtained by flipping out the insertion cassettes as described by Datsenko \& Wanner (2000).

Cells were grown at 28 or $37{ }^{\circ} \mathrm{C}$ under aeration (in liquid medium if not otherwise indicated). The medium used was Luria-Bertani (LB) broth (Miller, 1972). Antibiotics were added as recommended by Miller (1972). Growth was monitored by measuring $\mathrm{OD}_{578}$.

Construction of lacZ reporter fusions and their transfer into the chromosome. Single-copy lac $Z$ reporter fusions to the following $E$. coli GGDEF/EAL genes have been described previously: yaiC, ydaM, $y d d V$, yeal, yedQ, yciR and $y d i V$ (Weber et al., 2006), and yegE and $y$ hjH (Pesavento et al., 2008). The primers used to construct all other lacZ fusions are listed in Supplementary Table S1. The appropriate PCR fragments (depending on the chromosomal context of the specific genes) were cloned into the lac $Z$ fusion vector pJL28, as previously described (Weber et al., 2006). All fusions were translational fusions that included approximately 10 codons of the corresponding ORF (also making sure that no complete signal sequences were present in the fusion proteins) and contained at least $300 \mathrm{bp}$ upstream of the coding region (standard 'short fusions'). In cases (yeaI-yeaJ, yfiN, yliE-yliF, yneF) in which a gene could be part of an operon and would then not be the promoterproximal gene, additional lac $Z$ fusions were generated, which included the entire promoter-proximal gene(s) as well as at least $300 \mathrm{bp}$ of the non-coding upstream region ('long fusions'). For yeaI-yeaJ, expression of the respective 'short' and 'long' fusions was similar, indicating that these genes are monocistronic; the 'long' yfiN:: lacZ (including the upstream gene $y f i R$ ) showed weak activity, whereas the 'short' fusion seemed inactive, i.e. $y$ fi $\mathrm{N}$ seemed to be the second gene in an operon; the lac $Z$ fusions in $y n e F$ (also containing $y n e G$ and $y n e H$, which are located upstream of $y n e F$ in a putative operon; upstream of $y n e H$ is a putative transcriptional terminator) as well as those in yliE and yliF did not exhibit significant expression, i.e. it remains to be shown whether these genes are part of operons expressed under other conditions.

All reporter fusions were transferred to the $\operatorname{att}(\lambda)$ location of the chromosome via phage $\lambda$ RS45 or $\lambda$ RS74 (Simons et al., 1987). Single lysogeny was tested by a PCR approach (Powell et al., 1994).

SDS-PAGE and immunoblot analysis. Sample preparation for SDS-PAGE and immunoblot analysis were performed as described previously (Lange \& Hengge-Aronis, 1994). Cellular protein, 5 or $10 \mu \mathrm{g}$ per lane, was applied. Polyclonal sera against $\sigma^{\mathrm{S}}$ and $\mathrm{CsgD}$ (Weber et al., 2006), a goat anti-rabbit IgG alkaline phosphatase conjugate (Sigma) and a chromogenic substrate (BCIP/NBT, Boehringer Mannheim) were used.

Northern blot analysis. For RNA preparation and Northern blot analysis of $\operatorname{csg} \mathrm{D}$ mRNA, cells were grown in $\mathrm{LB}$ medium at $28^{\circ} \mathrm{C}$ and harvested at $\mathrm{OD}_{578}$ 4.0. The procedure and materials used were exactly as described previously (Weber et al., 2006).

$\boldsymbol{\beta}$-Galactosidase assay. $\beta$-Galactosidase activity was assayed by use of ONPG as a substrate and is reported as $\mu \mathrm{mol} o$-nitrophenol $\mathrm{min}^{-1}$ $(\mathrm{mg} \text { cellular protein })^{-1}$ (Miller, 1972). Experiments examining the expression of lac $Z$ fusions during the entire growth cycle were done at least twice, and a representative experiment is shown. For determin- 
ing $\beta$-galactosidase activities in cells grown on solid medium, cells were grown overnight in patches on LB agar plates and cells growing in the central parts of the patches were resuspended in Z-buffer (Miller, 1972). $\mathrm{OD}_{578}$ was determined and measurements were performed as with cells grown in liquid medium.

Bacterial motility assay. Motility was tested on swim plates containing $0.5 \%$ bacto-tryptone, $0.5 \% \mathrm{NaCl}$ and $0.3 \%$ agar. A $3 \mu \mathrm{l}$ volume of overnight culture (adjusted to $\mathrm{OD}_{578} 4.0$ in its own supernatant) was inoculated into the swim plates and cells were allowed to grow and swim for 4-6 h at the temperature indicated.

\section{RESULTS}

\section{GGDEF/EAL genes in E. coli and the construction of lacZ reporter fusions}

E. coli K-12 has 29 genes, which encode 12 proteins with GGDEF domains, 10 proteins with EAL domains and seven proteins that feature both domains. Some E. coli K-12 strains lack one of the EAL-only proteins [YahA; this also turned out to be the case for the W3110 strain used in our study. For a list of the $28 \mathrm{GGDEF} / \mathrm{EAL}$ genes present, see Table 1. Note that the order of GGDEF/EAL genes in all composite figures in this study is always the same as in Table 1, i.e. GGDEF-only, GGDEF + EAL and EAL-only genes (and within these subsets, in alphabetical order)]. As the physiological functions of most of these genes is still unknown, they carry $y$-designations (e.g. yaiC, $y d a M$, etc.; the only exception is $r t n$ ). We continue to use these $y$ designations as we think that currently at least there is no unifying basis for renaming these genes: (i) DGC and/or PDE activities of purified proteins in vitro have been determined for only a small minority of these proteins (Pesavento et al., 2008; Ryjenkov et al., 2005; Schmidt et al., 2005; Weber et al., 2006); (ii) whether the 'composite' GGDEF + EAL proteins have DGC and/or PDE activities (or none at all) is not unequivocally predictable; and (iii) in some proteins (YeaI, YhdA, YcgF, YdiV) the GGDEF

Table 1. Summary of sequence features and expression data of genes encoding GGDEF/EAL domain proteins in E. coli K-12

\begin{tabular}{|c|c|c|c|c|c|c|c|c|c|c|c|}
\hline Gene & b-Numb & & $\begin{array}{l}\mathrm{N} \text {-terminal } \\
\text { domains }\end{array}$ & $\begin{array}{l}\text { GGDEF domain }{ }^{1} \\
\text { I-site } \\
\text { R } x \times D \text {-site } \\
\text { GGDEF }\end{array}$ & $\begin{array}{l}\text { EAL do } \\
\text { EAL } \times R\end{array}$ & $\begin{array}{l}\operatorname{main}^{2}: \\
\text { C-di-GMP } \\
Q / \bar{R} / \bar{D} / \bar{D}\end{array}$ & $\begin{array}{l}\text { catalysis } \\
\mathrm{T} / \mathrm{E}\end{array}$ & $\begin{array}{l}\text { expression } \\
\text { in } \mathrm{LB}^{3}\end{array}$ & $\begin{array}{l}\text { highest expr } \\
\text { temperature }\end{array}$ & $\begin{array}{l}\text { ression at: } \\
\text { growth } \\
\text { phase }^{4}\end{array}$ & $\begin{array}{l}\text { regulated } \\
\text { by } \sigma^{s} \text { : }\end{array}$ \\
\hline \multicolumn{12}{|c|}{ GGDEF domain only: } \\
\hline yaic & b0385 & $*^{5}$ & MASE2 & RGSDVIGRFGGDEF & & & & ++ & $28^{\circ} \mathrm{C}$ & SP & pos \\
\hline YcdT & b1025 & * & $?$ & RPDDLLARVGGDEF & & & & + & $28=37^{\circ} \mathrm{C}$ & LP & - \\
\hline ydaM & b1341 & & ?-PAS & RKGDLVFRWGGDEF & & & & +++ & $28^{\circ} \mathrm{C} / 37^{\circ} \mathrm{C}$ & SP & pos \\
\hline$y d d V$ & b1490 & & $?$ & RSSDYVFRYGGDEF & & & & +++ & $28^{\circ} \mathrm{C} / 37^{\circ} \mathrm{C}$ & SP & pos \\
\hline ydeH & b1535 & & ? & RDYETVYRYGGEEF & & & & ++ & $28=37^{\circ} \mathrm{C}$ & $L P / S P$ & neg \\
\hline yeaI & b1785 & * & ? & RPDDILARLEGEVF & & & & - & - & - & \\
\hline yeaJ & b1786 & * & ? & RKSDYAIRLGGDEF & & & & +++ & $28^{\circ} \mathrm{C} / 37^{\circ} \mathrm{C}$ & late LP/SP & - \\
\hline yeaP & b1794 & & GAF & QNGEVIGRLGGDEF & & & & ++ & $28=37^{\circ} \mathrm{C}$ & LP & - \\
\hline yedo & b1956 & * & $?$ & RAQDVAGRVGGDEF & & & & ++ & $28=37^{\circ} \mathrm{C}$ & $L P / S P$ & pos \\
\hline YfiN & b2604 & * & ? & GLRHKAYRLGGDEF & & & & + & $28=37^{\circ} \mathrm{C}$ & LP & - \\
\hline YliF & b0834 & * & ? & VDKGKVYRFGGDEF & & & & - & - & - & \\
\hline YneF & b1522 & * & ? & GDKGLVARMGGDEF & & & & - & - & - & \\
\hline \multicolumn{12}{|c|}{ GGDEF + EAL domains: } \\
\hline$y C i R$ & b1285 & & PAS & EHDQVLARPGGDEF & EALVR & $\bar{Q} / \mathrm{R} / \bar{D} / \bar{D}$ & $\mathrm{~T} / \overline{\mathrm{E}}$ & ++ & $28=37^{\circ} \mathrm{C}$ & $\mathrm{LP} / \mathrm{SP}$ & pos \\
\hline$y d d U$ & b1489 & & PAS-PAS & KPDQYLCRIEGTQF & EALAR & $\mathrm{Q} / \mathrm{R} / \mathrm{D} / \mathrm{D}$ & $\mathrm{T} / \mathrm{E}$ & +++ & $28^{\circ} \mathrm{C} / 37^{\circ} \mathrm{C}$ & SP & pos \\
\hline yegE & b2067 & * & MASE1-PAS 3 & RSSDVVLARLGGDEF & EARNL & $-1-1-1-$ & $-1-$ & ++ & $28=37^{\circ} \mathrm{C}$ & $\mathrm{LP} / \mathrm{SP}$ & pos \\
\hline$y f e A$ & b2395 & * & MASE 1 & QENEKLYQLPGSEL & EILAR & $Q / R / D / D$ & $\mathrm{~T} / \mathrm{E}$ & ++ & $28=37^{\circ} \mathrm{C}$ & LP & neg \\
\hline$y f g F$ & b2503 & * & MASE 1 & EPGEDVYQLSGNDL & EILLR & $Q / R / D / D$ & $\mathrm{~T} / \mathrm{E}$ & - & - & - & \\
\hline YhdA & b3252 & * & $?$ & YPGALLARYHRSDF & ELMCR & $Q / R /-1-$ & $-1-$ & + & $28=37^{\circ} \mathrm{C}$ & LP & - \\
\hline$y h j k$ & b3529 & * & ? & SPRMILAQISGYDF & EVLLR & $\mathrm{Q} / \mathrm{R} / \mathrm{D} / \overline{\mathrm{D}}$ & $\mathrm{T} / \overline{\mathrm{E}}$ & ++ & $28^{\circ} \mathrm{C}$ & SP & - \\
\hline \multicolumn{12}{|c|}{ EAL domain only: } \\
\hline rtn & b2176 & $*$ & ? & & EVLLR & $\mathrm{Q} / \overline{\mathrm{R}} / \overline{\mathrm{D}} / \overline{\mathrm{D}}$ & $\bar{T} / \bar{E}$ & ++ & $28=37^{\circ} \mathrm{C}$ & LP & neg \\
\hline$y c g F$ & b1 163 & & BLUF & & EAIVQ & $-1-1-1-$ & $\mathrm{T} / \mathrm{-}$ & +++ & $28^{\circ} \mathrm{C}$ & LP & neg \\
\hline$y \subset g G$ & b1168 & * & $?$ & & EVLAR & $Q / R / D / D$ & $\mathrm{~T} / \mathrm{E}$ & - & - & - & \\
\hline ydiv & b1707 & & - & & ----- & $-1-1-1-$ & $-1-$ & - & - & - & \\
\hline$y h j H$ & b3525 & & - & & ELLTV & $Q /-/ D /-$ & $-/ \mathrm{E}$ & +++ & $28=37^{\circ} \mathrm{C}$ & late LP & neg \\
\hline$y j c C$ & b4061 & * & ? & & EALLR & $\mathrm{Q} / \mathrm{R} / \mathrm{D} / \mathrm{D}$ & $\mathrm{T} / \mathrm{E}$ & ++ & $28=37^{\circ} \mathrm{C}$ & $\mathrm{sP}$ & pos \\
\hline$y 1 a B$ & b0 457 & * & ? & & EALAR & $Q / R / D / D$ & $\mathrm{~T} / \mathrm{E}$ & ++ & $28=37^{\circ} \mathrm{C}$ & $L P / S P$ & pos \\
\hline$Y 1 i E$ & b0833 & * & $?$ & & EALCR & $\mathrm{Q} / \mathrm{R} / \mathrm{D} / \mathrm{D}$ & $\mathrm{T} / \mathrm{E}$ & - & - & - & \\
\hline yoad & b1815 & * & $?$ & & EILLR & $Q / R / D / D$ & $\mathbb{T} / \mathrm{E}$ & ++ & $28^{\circ} \mathrm{C} / 37^{\circ} \mathrm{C}$ & SP & pos \\
\hline
\end{tabular}

${ }^{1}$ I-site, inhibitory binding site for c-di-GMP; A-site, GTP-binding and enzyme active site (consensus is GGDEF or GGEEF).

${ }^{2}$ According to Rao et al. (2008), the EAL motif is involved in coordinating $\mathrm{Mg}^{2+}$, four amino acids (Q, R, D, D) dispersed along the primary sequence are required for c-di-GMP binding (the $\mathrm{R}$ is the one that follows the EAL motif with one non-conserved amino acid in between), and two amino acids (T, E) are directly involved in catalysis. Note that also the proteins in which most or even all of these functionally relevant amino acids are not present, are clearly identified as EAL domains by the BLAST algorithm.

${ }^{3}$ For expression data, see Fig. $1 ;+++,++,+$, maximal specific $\beta$-galactosidase activity measured was $>0.1,>0.01$ or $>0.002 \mu \mathrm{mol} \mathrm{min}{ }^{-1}(\mathrm{mg}$ total cellular protein $)^{-1}$, respectively.

${ }^{4} \mathrm{LP}$, exponential growth phase; SP, stationary phase; if a gene exhibits predominant (but not exclusive) expression at one temperature or in one growth phase, this is highlighted in bold type.

${ }^{5}$ Protein contains transmembrane domains. 
and/or EAL motifs (which essentially contribute to the enzyme activity) are degenerate (Table 1), and therefore these proteins are highly unlikely to synthesize or degrade c-di-GMP.

In order to study the regulation of expression of all genes encoding GGDEF/EAL domain proteins in E. coli K-12, we generated single-copy lac $Z$ reporter fusions to all of them. These reporter fusions mainly reflect transcription of these genes, but also contain the translational start site and approximately 10 codons of the respective genes fused to lac $Z$, and therefore also take into account putative differences in translation initiation efficiencies of the respective proteins. As all reporter fusions were constructed in the same way, the $\beta$-galactosidase activities measured allowed not only monitoring of the dynamics of expression of specific single genes, but also a rough comparison of expression levels among such genes. The length of upstream DNA present and fusion construction in cases in which GGDEF/EAL genes could be part of an operon (yeaI-yeaJ, yfiN, yliE-yliF, yneF) are described in detail in Methods. In the single case in which an operon structure had been clearly demonstrated earlier, i.e. for $y d d V-y d d U$ (Méndez-Ortiz et al., 2006), we studied a $y d d V:$ :lacZ fusion alone. Overall, at least 22 of the 28 GGDEF/EAL genes in E. coli $\mathrm{K}-12$ seem to be expressed as single-gene transcriptional units (for details, see Methods).

\section{Expression patterns of all $E$. coli genes encoding GGDEF/EAL domain proteins as a function of growth phase and temperature}

For both E. coli and Salmonella, certain GGDEF/EAL proteins have been implicated in the control of motility and the expression of adhesive curli fimbriae. As motility genes are transiently expressed during the post-exponential phase of the growth cycle and curli expression occurs during entry into stationary phase, we monitored the expression of the lac $Z$ reporter fusions to all GGDEF/EAL domain-encoding genes as a function of growth phase (Fig. 1). Moreover, as curli expression specifically occurs at temperatures below $30{ }^{\circ} \mathrm{C}$ only (Olsén et al., 1989), we compared the expression patterns of all fusions at 37 and $28{ }^{\circ} \mathrm{C}$ (shown in Fig. 1a and b, respectively).

First of all, the majority of the E. coli GGDEF/EAL domainencoding genes were indeed expressed (21/28). Fusions to only seven genes, i.e. yeaI, yliF, yneF, yfgF, ycgG, ydiV and yliE, exhibited baseline $\beta$-galactosidase levels [0.001$0.002 \mu \mathrm{mol} \mathrm{min}^{-1}$ (mg total cellular protein $)^{-1}$, see summarized data in Table 1]. The other genes showed a wide range of expression levels with more than two orders of magnitude difference. At the lower end, there was $y h d A$, which nevertheless produced a clear phenotype when knocked out (see below). Among the most strongly expressed genes were yeaJ and $y d d V$ (both encoding GGDEF-only proteins), as well as $y h j H$ (encoding an EAL-only protein). Even these genes, however, belong to the rather moderately expressed genes in E. coli, as judged by comparison with the highly expressed genes seen by microarray analysis as well as by the assay of similarly constructed lac $Z$ fusions (our unpublished data).

Expression patterns of GGDEF/EAL domain-encoding genes as a function of growth phase were very different, with two major types becoming apparent (Fig. 1a, b, and summary in Table 1): (i) genes predominantly expressed during exponential or post-exponential phase (showing at least constant or increasing $\beta$-galactosidase activities in the growing cultures); and (ii) genes that exhibited induction during entry into stationary phase (showing increasing $\beta$ galactosidase activities, while culture growth slowed down and finally stopped). Representatives of the first group included yeaJ, yeaP, yfeA and $y h j \mathrm{H}$. Genes induced during transition into stationary phase included $y d a M, y d d V, y c i R$, yegE, yjcC, ylaB and yoaD. Especially at $28{ }^{\circ} \mathrm{C}$ (Fig. 1b), at which cells grow more slowly, differences in the timing of induction during entry into stationary phase also became apparent: some genes were activated relatively early during entry into stationary phase, e.g. $y d a M, y d d V$ and $y e g E$, whereas yaiC and yoaD were induced significantly later (with yaiC also showing expression at $28{ }^{\circ} \mathrm{C}$ alone).

At least eight of the 21 expressed GGDEF/EAL genes exhibited differential temperature regulation (compare patterns in Fig. 1a and b, summary in Table 1). While seven of these genes were increasingly or even exclusively expressed at $28{ }^{\circ} \mathrm{C}$ ( $y a i C, y d a M, y d d V / y d d U$, yhjK, ycgF and yoaD), a single gene (yeaJ) was slightly preferentially expressed at $37^{\circ} \mathrm{C}$. Thus, the overall tendency for temperature regulation of GGDEF/EAL domain-encoding genes is towards increased expression at temperatures below $37^{\circ} \mathrm{C}$.

\section{The majority of expressed genes encoding GGDEF/EAL domain proteins are under the control of the general stress sigma factor $\sigma^{\mathrm{S}}$}

Stationary phase induction of gene expression suggested regulation by the general stress and stationary phase sigma factor $\sigma^{\mathrm{S}}$. Indeed, $\sigma^{\mathrm{S}}$ control has been previously observed for a subset of E. coli GGDEF/EAL domain-encoding genes (although in a different strain background; Weber et al., 2006). Therefore, the systematic analysis of expression patterns of all our reporter fusions at both temperatures was also performed in a $\sigma^{\mathrm{s}}$-deficient rpoS mutant background (Fig. 1; data represented by circles in all panels). In practically all cases in which a GGDEF/EAL domain-encoding gene was clearly activated during entry into stationary phase, the increase in expression was $\sigma^{\mathrm{S}}$ dependent (yaiC, ydaM, yddV/yddU, yedQ, yciR, yegE, yjcC, ylaB and yoaD). Thus, 10 out of the 21 expressed GGDEF/ EAL domain-encoding genes were under the significant positive control of $\sigma^{\mathrm{S}}$.

Interestingly, several genes predominantly expressed during the exponential or post-exponential phase appeared to be negatively $\sigma^{\mathrm{S}}$-regulated. This was most apparent for 
(a)
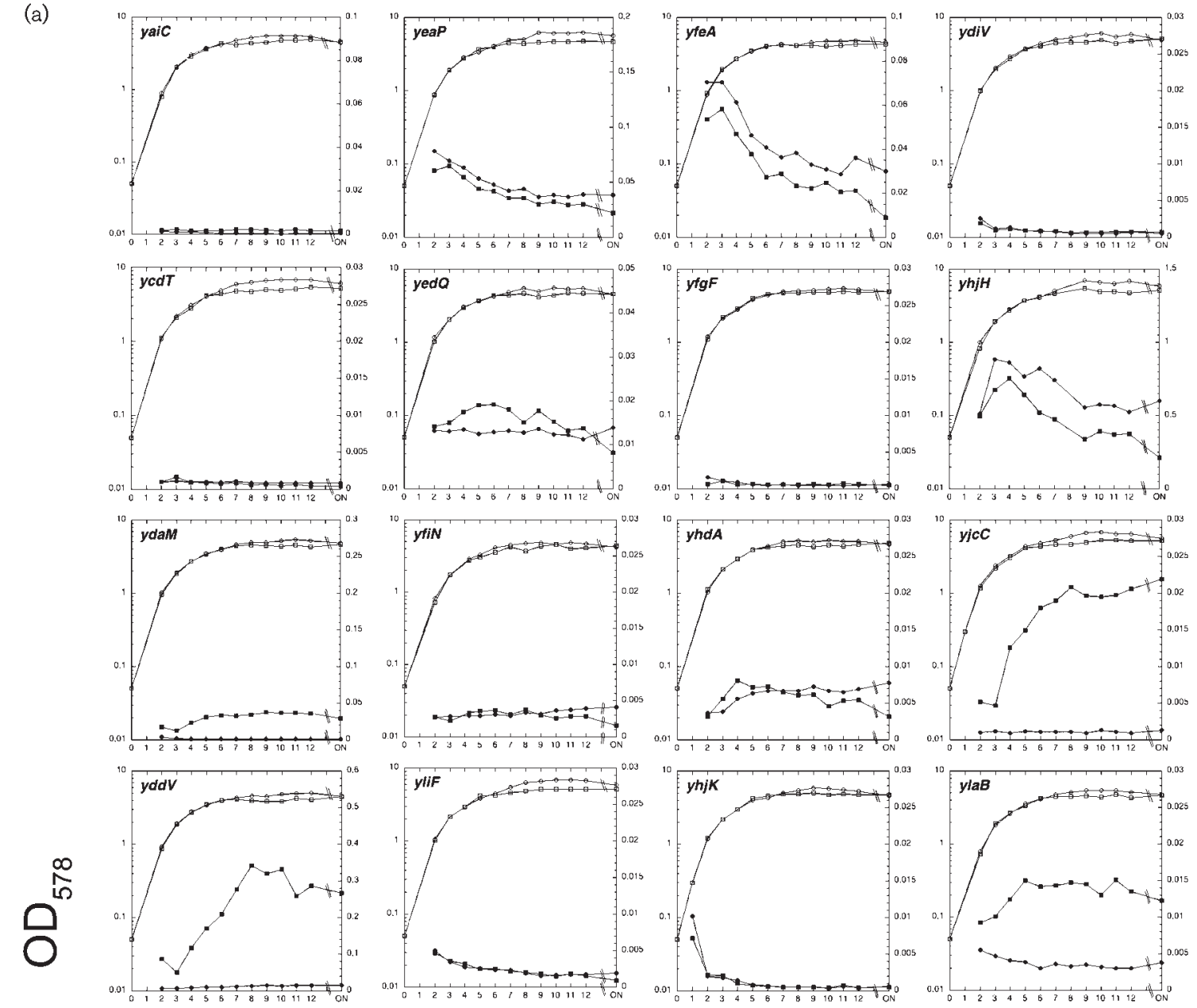

$\frac{0}{8}$
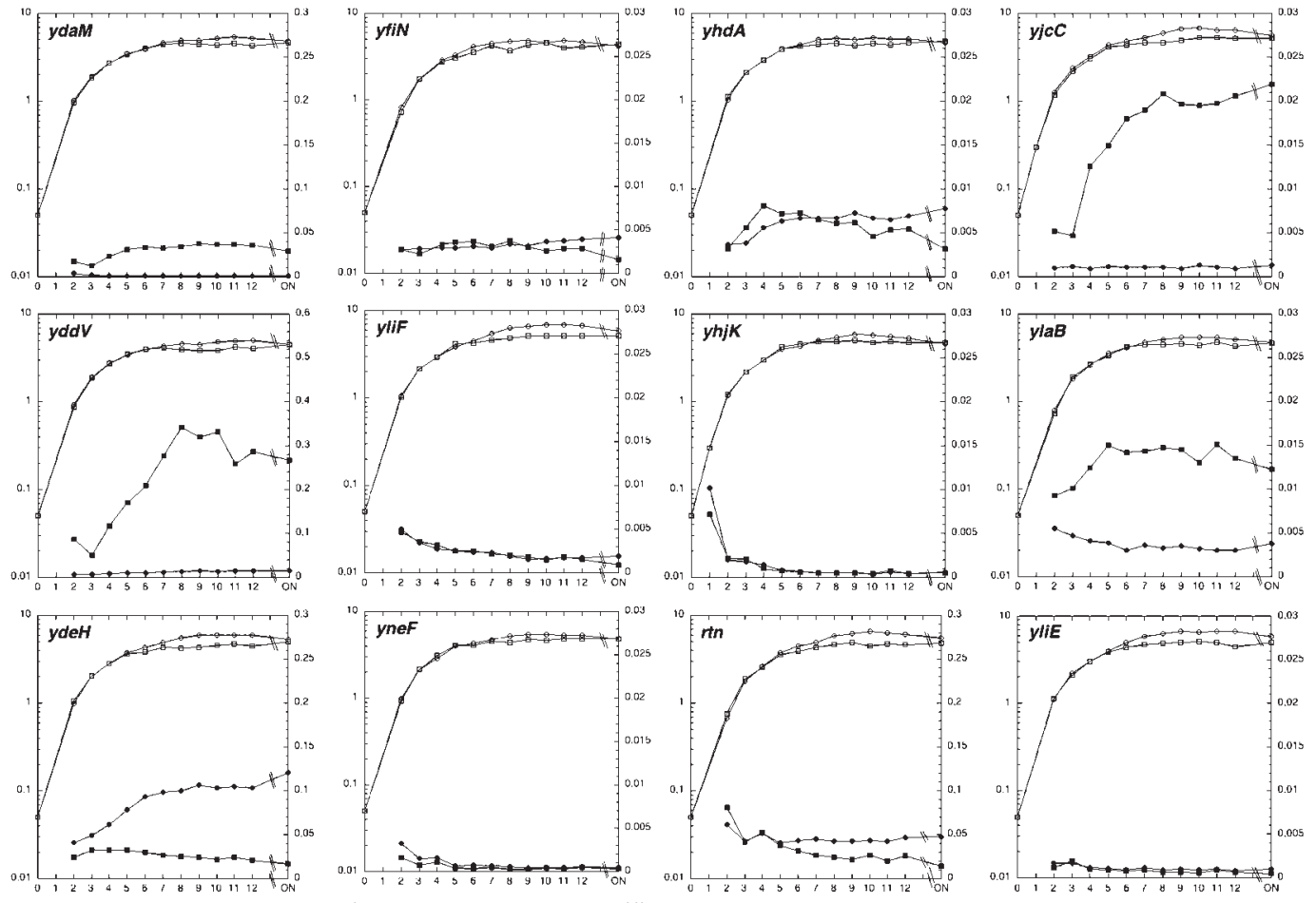

?.
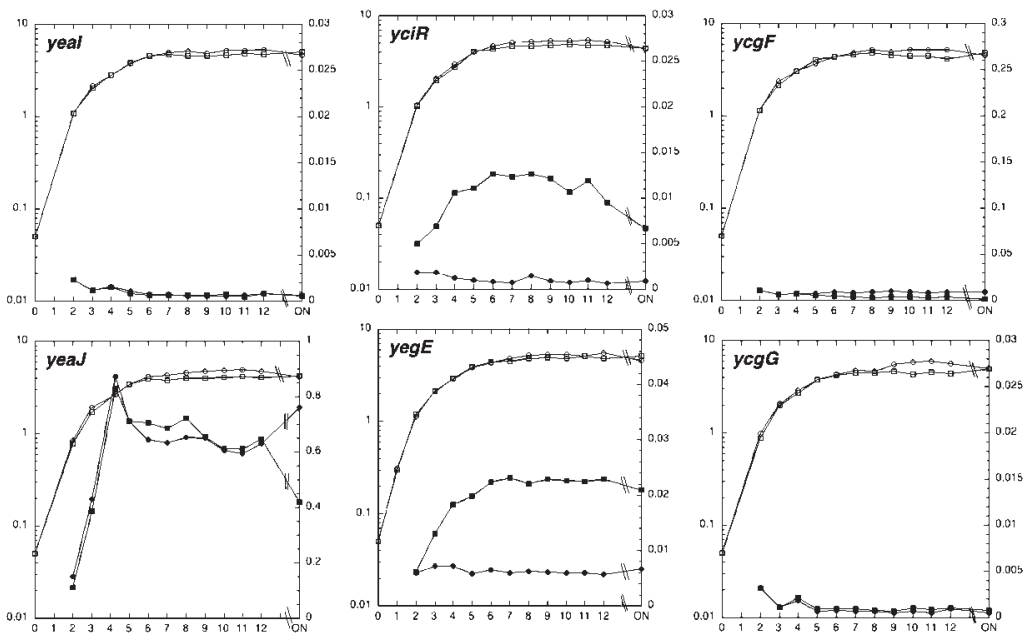

Time (h) 
(b)
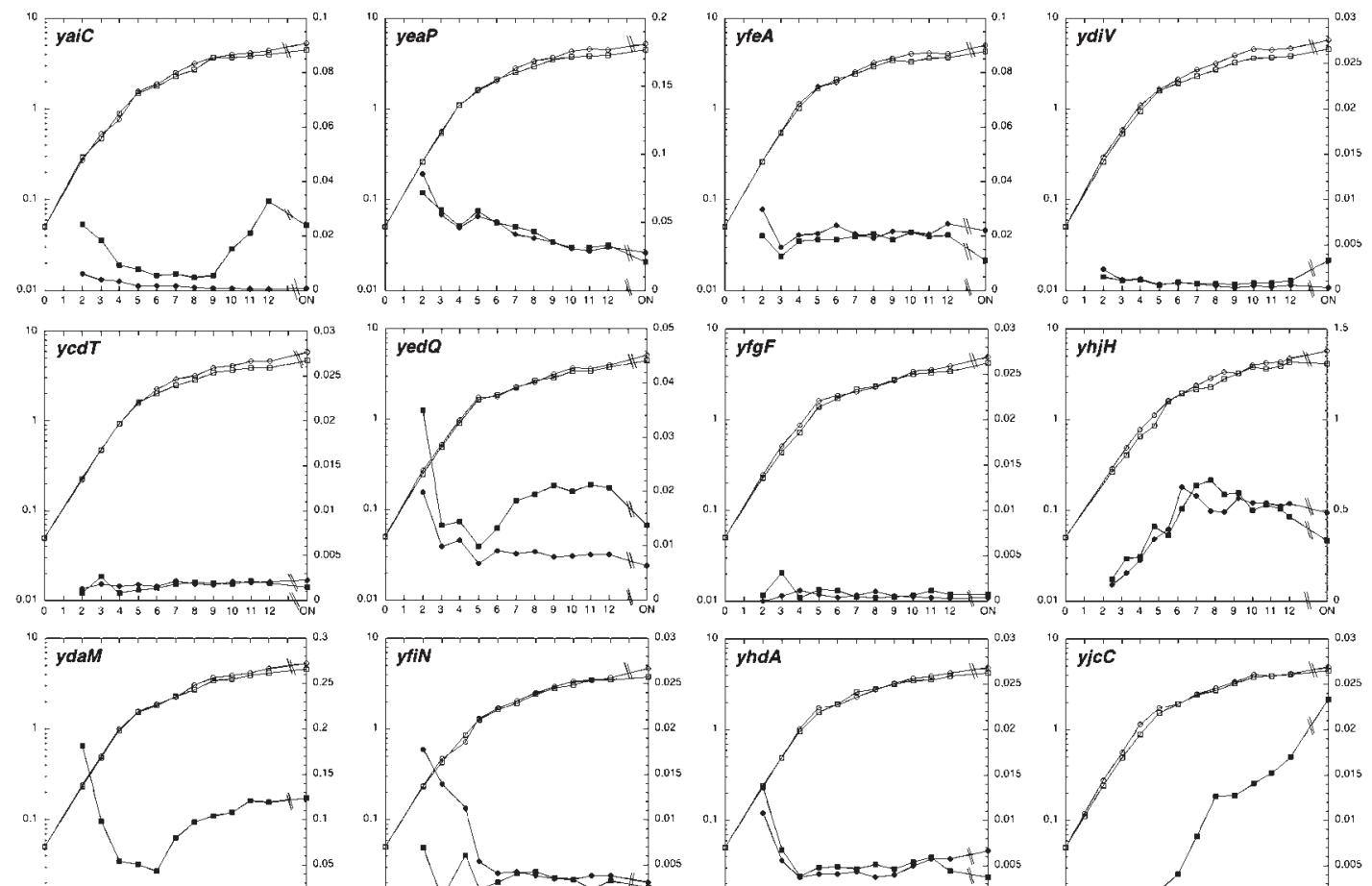

\begin{tabular}{l}
0 \\
8 \\
$\mathbb{D}$ \\
\hline
\end{tabular}
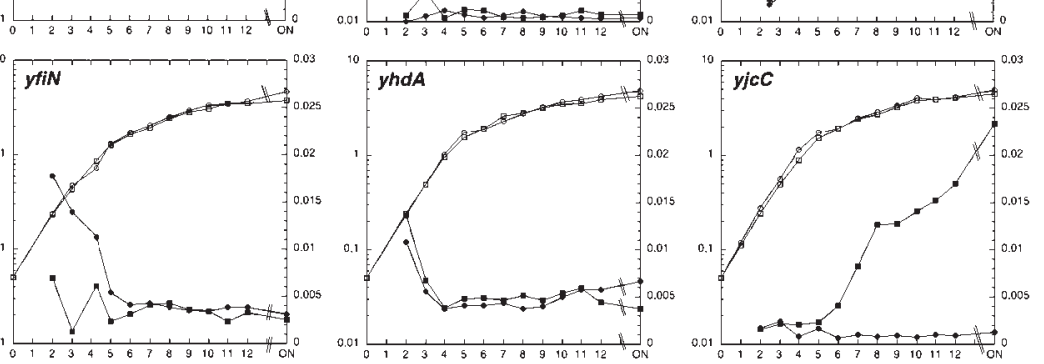

$\stackrel{\varrho}{\overline{\bar{\Omega}}}$
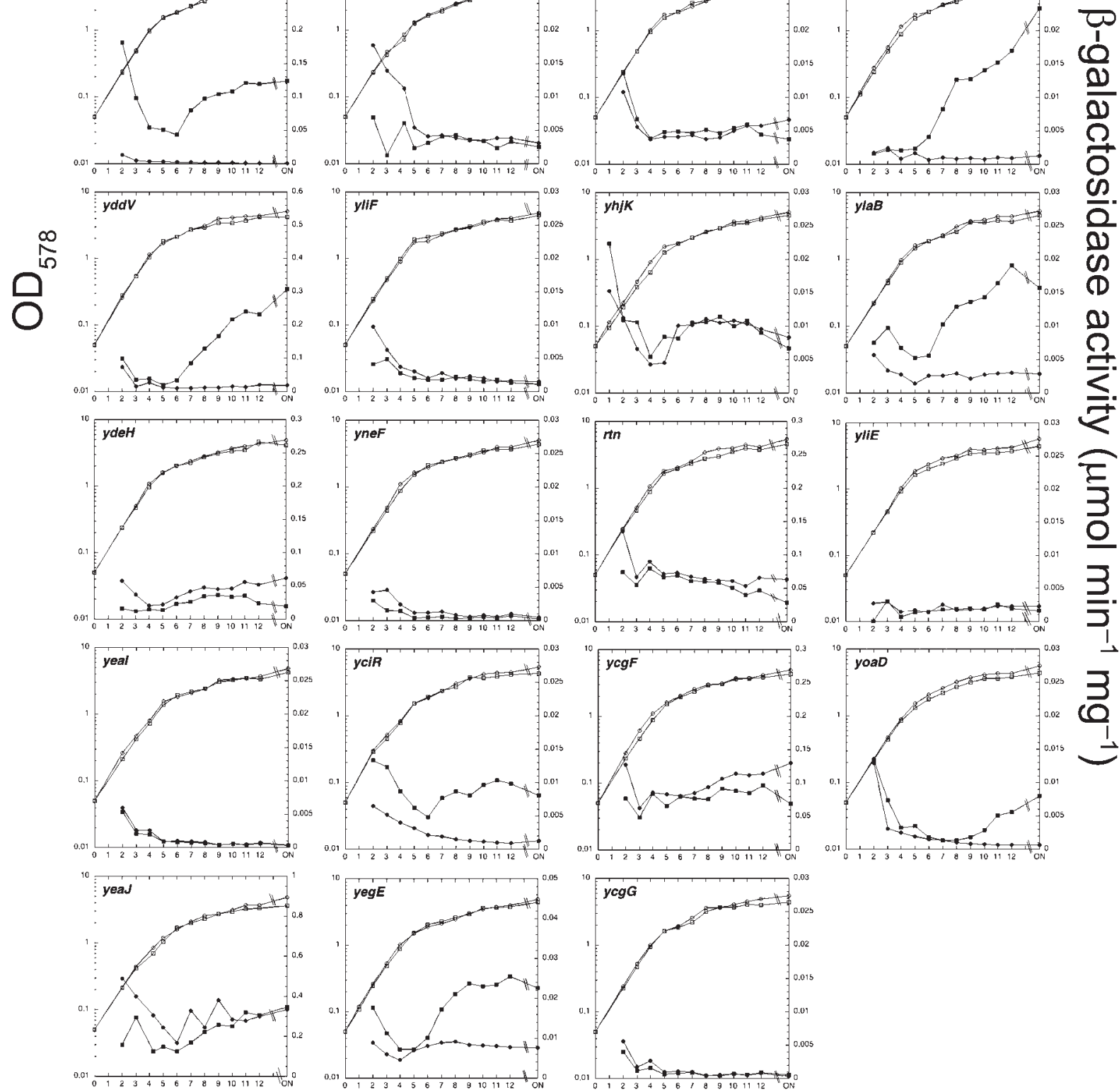

Time (h) 
Fig. 1. Expression of GGDEF/EAL genes of E. coli during the growth cycle in liquid LB medium. Derivatives of strain W3110 carrying single-copy lacZ fusions in the GGDEF/EAL genes indicated in the respective panels were grown in $\mathrm{LB}$ at $37{ }^{\circ} \mathrm{C}(\mathrm{a})$ or $28{ }^{\circ} \mathrm{C}$ (b). For all fusions, otherwise isogenic $r p o S^{+}$(squares) and rpoS::Tn10 (circles) strains were tested. OD ${ }_{578}(o p e n$ symbols) and specific $\beta$-galactosidase activities (filled symbols) were determined along the growth curve. ON, overnight culture (24 $\mathrm{h}$ after starting the experiment).

$y d e H$ (encoding a GGDEF-only protein), which in the absence of $\sigma^{\mathrm{S}}$ revealed a potential for stationary phase induction or inverse growth-rate regulation that remained cryptic in the wild-type background (at $37{ }^{\circ} \mathrm{C}$; circles in Fig. 1 represent the $r p o S$ mutant data). At $37^{\circ} \mathrm{C}, y f e A, r t n$ and $y h j H$ also exhibited higher expression in the rpoS mutant (all three encode proteins with EAL domains). This negative control by $\sigma^{\mathrm{S}}$ became more pronounced when cells were grown on solid rather than in liquid medium (Fig. 2; in addition to the aforementioned genes, $y c g F$ also
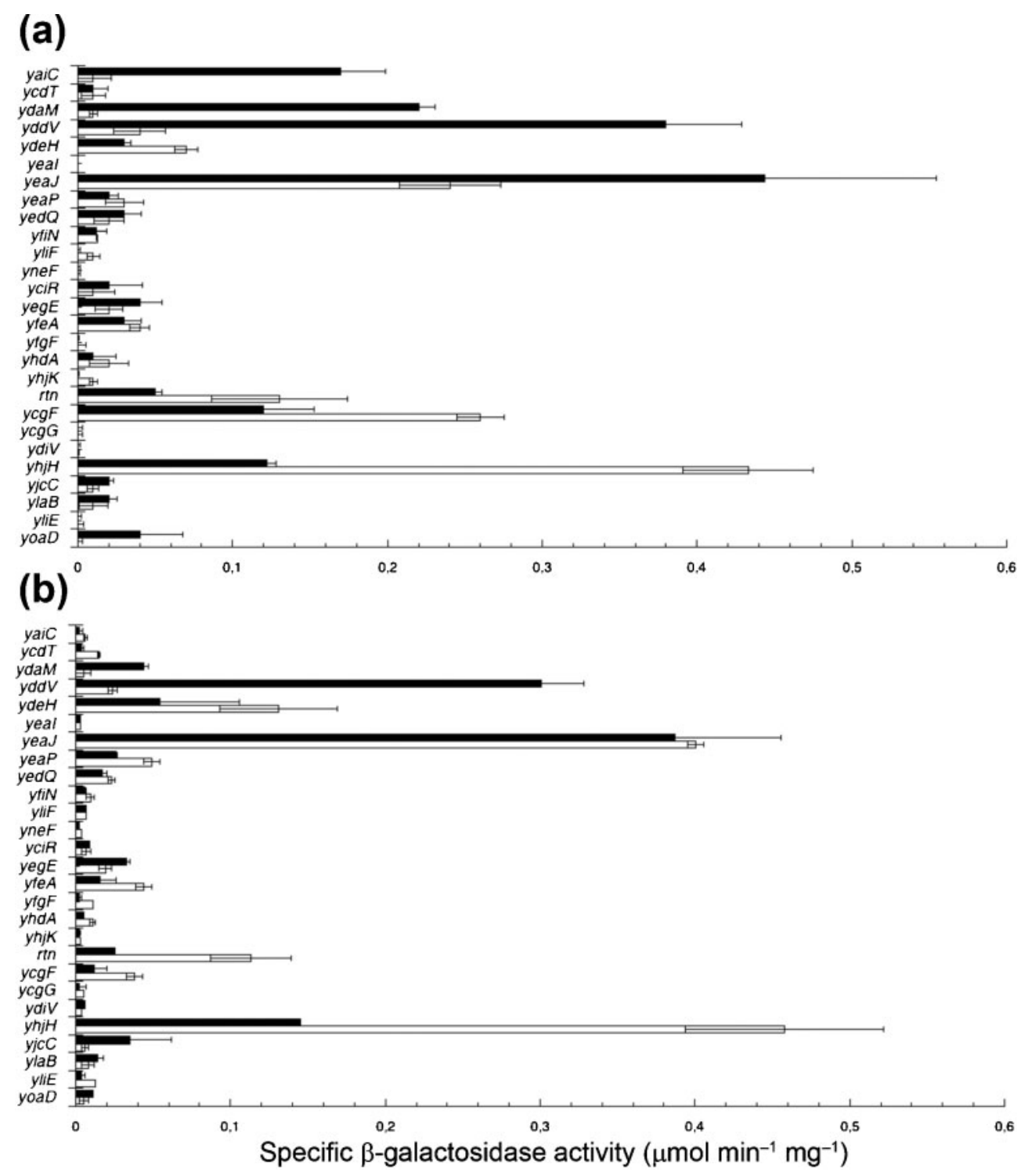

Fig. 2. Expression of GGDEF/EAL genes of $E$. coli after overnight growth on LB plates. The same lacZ fusion strains as used in Fig. 1 were grown overnight in patches on LB plates incubated at $28^{\circ} \mathrm{C}(\mathrm{a})$ or $37^{\circ} \mathrm{C}(\mathrm{b})$. Cells from the central part of the patches were scratched from the agar plates and resuspended, and $\mathrm{OD}_{578}$ and specific $\beta$-galactosidase activities (represented by the bars) were determined. As in Fig. 1, activities of all fusions were determined in otherwise isogenic rpoS ${ }^{+}$(black bars) and rpoS: : $\operatorname{Tn} 10$ (white bars) backgrounds. The entire experiment was done three times independently and mean activity \pm SD is shown. 
showed enhanced expression in the rpoS mutant under these conditions).

We conclude that $\sigma^{\mathrm{S}}$ directs a major reorganization of the expression of genes encoding GGDEF/EAL proteins during entry into stationary phase. While downregulated genes mainly encode EAL proteins, more strongly expressed genes encode both DGCs and PDEs (both proven and putative).

\section{Differential expression of GGDEF/EAL domain- encoding genes on liquid and solid medium}

A bacterial colony on an agar surface represents a biofilm at a solid wet medium-air interface. Curli fimbriae and cellulose as a biofilm matrix component contribute to the highly structured morphology of such colony biofilms and the formation of these components is stimulated by high cellular c-di-GMP levels (Römling, 2005). We therefore tested whether any of the E. coli genes encoding GGDEF/ EAL proteins exhibited altered expression during growth on agar plates in comparison with liquid medium (Fig. 2). Four genes were more strongly expressed on solid medium (compare data in Fig. 2 and Fig. 1): (i) yaiC (sixfold higher expression on plates incubated at $28{ }^{\circ} \mathrm{C}$; again no expression at $37{ }^{\circ} \mathrm{C}$ ); (ii) $y d a M$ (twofold higher expression on plates at $28{ }^{\circ} \mathrm{C}$, but tenfold higher expression on plates at $37{ }^{\circ} \mathrm{C}$; also, expression was now similar at 28 and $37^{\circ} \mathrm{C}$, i.e. temperature regulation of $y d a M$ could be seen only in liquid medium); (iii) $y c i R$ (twofold higher expression on plates at $28{ }^{\circ} \mathrm{C}$, no difference at $37^{\circ} \mathrm{C}$ ); and (iv) yoaD (fivefold higher expression on plates at $28{ }^{\circ} \mathrm{C}$, twofold only at $37^{\circ} \mathrm{C}$ ). Only a single gene, $y h j H$, was downregulated during growth on solid medium (fourfold at both 28 and $37^{\circ} \mathrm{C}$ ). This differential regulation becomes particularly significant when seen against the background of all the other GGDEF/EAL genes, which showed remarkably similar expression levels in plate-grown colonies (Fig. 2) and during entry into stationary phase in liquid medium (Fig. 1).

In addition, growth on solid medium was characterized by a clear dominance of GGDEF proteins over EAL proteins (especially at $28^{\circ} \mathrm{C}$, the GGDEF-only proteins YaiC, YdaM, YddV and YeaJ were the major proteins expressed from the entire GGDEF/EAL family; see Fig. 2a). This suggests increased total DCG activity and therefore c-di-GMP accumulation when cells grow on a solid agar surface.

\section{Analysis of knockout mutations in all GGDEF/EAL domain-encoding genes: six genes are differentially involved in the control of the biofilm regulator CsgD and curli fimbriae expression}

Our knowledge of the expression patterns of all GGDEF/ EAL genes was now able to guide the search for their specific physiological functions. For phenotypic analyses, we isolated knockout mutations in all 28 genes encoding GGDEF/EAL proteins (for details, see Methods). Positive
c-di-GMP control has been shown for the expression of adhesive curli fimbriae in E. coli and Salmonella (reviewed by Römling et al., 2005). Curli expression occurs during entry into stationary phase (at temperatures below $30{ }^{\circ} \mathrm{C}$ ). It is strictly dependent on the general stress sigma factor $\sigma^{\mathrm{S}}$, which activates the expression of MlrA, a transcriptional activator that cooperates with $\sigma^{\mathrm{S}}$-containing RNA polymerase (RNAP) to activate the expression of CsgD, which acts as an essential activator that together with vegetative RNAP turns on the expression of the curli structural operon csgBAC (Brown et al., 2001; Gerstel et al., 2003; Römling et al., 2000; Weber et al., 2006). In E. coli, YdaM and YegE (a proven and a hypothetical DGC, respectively) also positively control $\operatorname{csg} D$ transcription, whereas the PDEs YciR and YhjH play the opposite role (Pesavento et al., 2008; Weber et al., 2006). Our finding that a majority of GGDEF/EAL domain-encoding genes in E. coli are expressed between late-exponential phase and entry into stationary phase raises the question of whether any other genes besides $y d a M, y e g E, y c i R$ and $y h j H$ also modulate curli formation.

To address this question, we first determined expression of the curli structural operon (i.e. the output of the entire cascade) with a single-copy $\operatorname{csg} B$ : lac $Z$ reporter fusion. Besides the four mutations previously observed to affect $\operatorname{csg} B$ : : lac $Z$ expression, mutations in yeaP and $y h d A$ also reduced $\operatorname{csg} B$ : : lac $Z$ expression (Fig. $3 \mathrm{a}$ ). The remaining 22 GGDEF/EAL knockout mutations did not affect $\operatorname{csg} B$ : : lacZ expression under the conditions tested (data not shown). Consistent with impaired curli formation, the mutants with strongly reduced $\operatorname{csg} B$ : : lacZ expression ( $y d a M, y e g E$ and $y h d A$ ) also showed reduced biofilm formation, visible as the attachment of cells in a ring-like formation when cultures were grown in rolling glass tubes (data not shown). Just like the mutations in $y d a M$ and $y e g E$, the $y h d A$ mutation also strongly diminished the expression of a second target gene of CsgD, yaiC (encoding a GGDEF protein required for cellulose synthesis). The yeaP mutation, however, reduced curli expression only partially (Fig. 3a) and did not affect yaiC expression (Fig. 3b).

In order to see where in the curli control cascade these mutations have an effect, we followed the accumulation of the master regulator $\sigma^{\mathrm{S}}$ and of the essential curli activator CsgD during entry into stationary phase by immunoblot analysis. In the wild-type background, the accumulation of $\sigma^{\mathrm{S}}$ is essentially complete at $\mathrm{OD}_{578} 2$, whereas induction of CsgD starts only at $\mathrm{OD}_{578} 3$ and is complete at $\mathrm{OD}_{578} 4$ and above (Fig. 4). While none of the GGDEF/EAL knockout mutations significantly affected $\sigma^{\mathrm{S}}$ levels, five mutations clearly altered CsgD levels and/or the kinetics of CsgD induction during entry into stationary phase (Fig. 4): besides the mutations in $y d a M, y c i R$, yegE and $y h j H$ (which affected CsgD levels as expected, see above), the mutation in $y h d A$ also strongly reduced the induction of CsgD during entry into stationary phase. The yeaP mutation, however, did not significantly change CsgD accumulation (Fig. 4). 

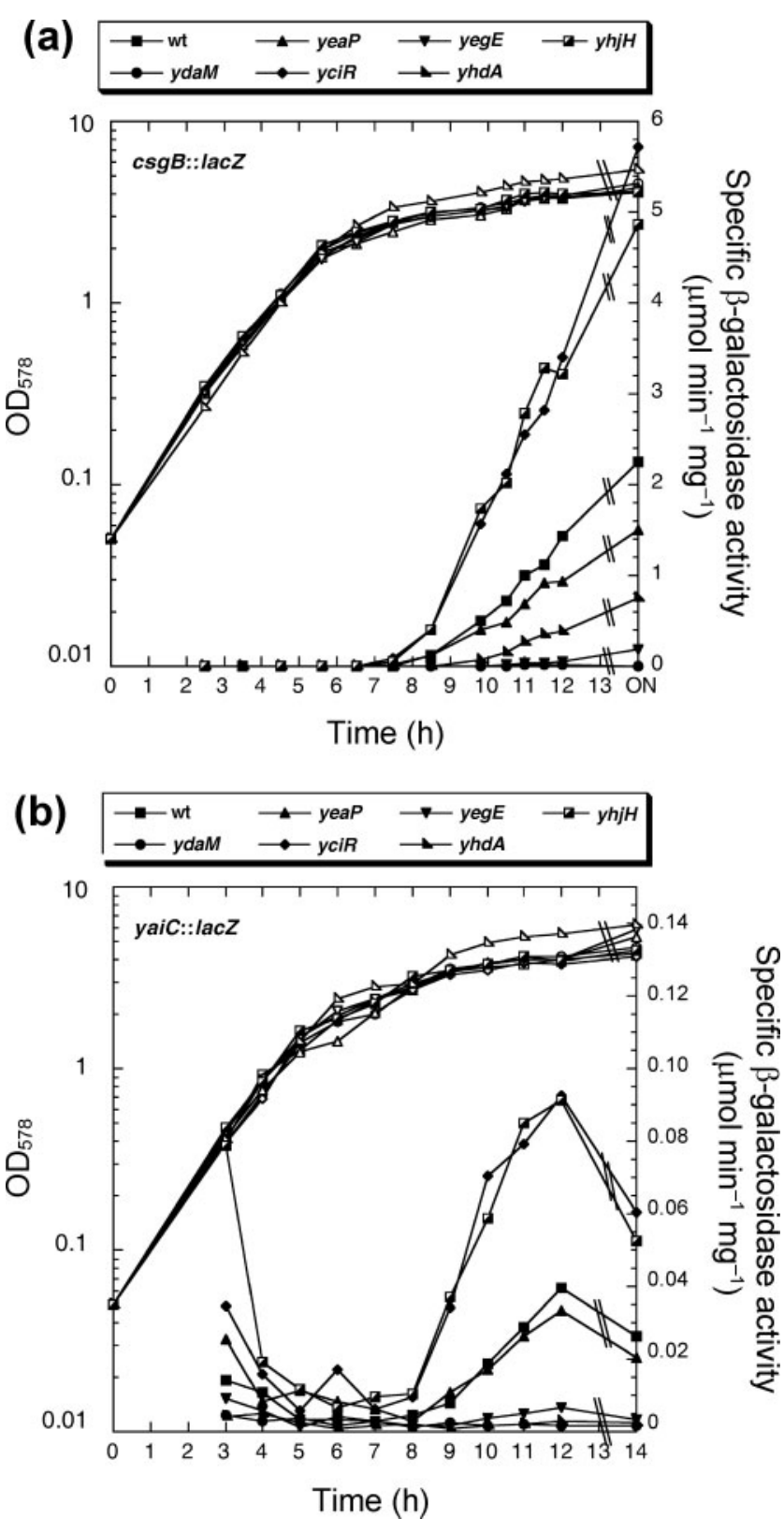

Fig. 3. Knockout mutations in several E. coli GGDEF/EAL genes change the expression of curli genes and the second CsgD target gene, yaiC. A W3110 derivative carrying the single-copy reporter fusions $\operatorname{csg} B$ : :lacZ (a) or yaiC::lacZ (b), as well as the derivatives carrying knockout mutations in $y d a M, y c i R$, yegE, $y h j H$, yhd $A$ and yeaP, were grown in LB at $28{ }^{\circ} \mathrm{C} . \mathrm{OD}_{578}$ (open symbols) and specific $\beta$-galactosidase activities (filled symbols) were determined along the growth curve. For symbols for the respective mutants, see the top of each panel. wt, Wild-type.

Because of its strong effect, the $y$ hdA mutation was further analysed (Fig. 5). This mutation not only strongly reduced CsgD protein levels (Fig. 4) but also csgD mRNA levels (Fig. 5b). Besides $\sigma^{\mathrm{S}}$, at least two factors are essential for $\operatorname{csg} D$ transcription, the MerR-like activator MlrA and the
DGC YdaM. Using lacZ fusions to the $m l r A$ and $y d a M$ genes, we therefore tested whether the $y h d A$ mutation alters MlrA and/or YdaM expression. No effect was found for the $m l r A:$ : lac $Z$ fusion (data not shown), but $y d a M:$ : lac $Z$ expression was reduced in the $y h d A$ mutant background (Fig. 5a). In the $y h d A$ mutant, expression of the flagellar master regulator FlhDC (assayed with a translational flhDC: : lacZ fusion that also reflects post-transcriptional control) was also shut off earlier during entry into stationary phase (Fig. 5c), and the $y$ hdA mutant showed reduced motility on swim plates (Fig. $5 \mathrm{~d}$ ). These data are in line with an earlier report that shows an indirect positive role of YhdA in FlhDC expression (Suzuki et al., 2006). The yhdA mutation was actually the only one of all our GGDEF/EAL gene knockouts that had an effect on the expression of flhDC (data not shown). We conclude that YhdA not only positively modulates motility gene expression but also is required for curli expression. In the curli control cascade, YhdA stimulates the expression of the GGDEF protein YdaM, but the finding that its effect on CsgD (both on $\operatorname{csg} D$ mRNA and CsgD protein; Figs 4 and 5 ) is stronger than its effect on YdaM expression suggests that it also plays a second, more direct role in $\operatorname{csg} D$ expression.

\section{DISCUSSION}

\section{Expression patterns of all GGDEF/EAL genes in $E$. coli and implications for C-di-GMP-dependent regulatory scenarios}

To our knowledge, our study is the first to systematically analyse the expression of all genes encoding GGDEF/EAL proteins in a bacterial species, i.e. the expression of genes whose products in general control the synthesis and degradation of the signalling molecule c-di-GMP. The majority of these genes in E. coli $\mathrm{K}-12$ were expressed when cells were grown in liquid complex medium (21 of 28 GGDEF/EAL genes present in strain W3110), although their actual levels of expression and regulatory patterns varied greatly. Taking all data together, certain clear tendencies become apparent (Table 1): (i) there are different subsets of dominantly expressed GGDEF/EAL domain-encoding genes during different phases of the growth cycle; (ii) a majority of the expressed genes (15 of 21) are under the control of the general stress and stationary phase sigma factor $\sigma^{\mathrm{S}}$; (iii) a subset of genes exhibits stronger or even exclusive expression at reduced temperature $\left(28^{\circ} \mathrm{C}\right)$; and (iv) a distinct small group of genes shows higher expression during growth on solid medium in comparison with liquid medium.

Expression of GGDEF/EAL domain-encoding genes differs by more than two orders of magnitude, with just two genes dominantly expressed in growing cells: yeaJ, which encodes a GGDEF-only protein (with intact $\mathrm{A}$ - and I-site signatures, and therefore most likely DGC activity), and $y$ hjH, which is under class 3 flagellar control and encodes 


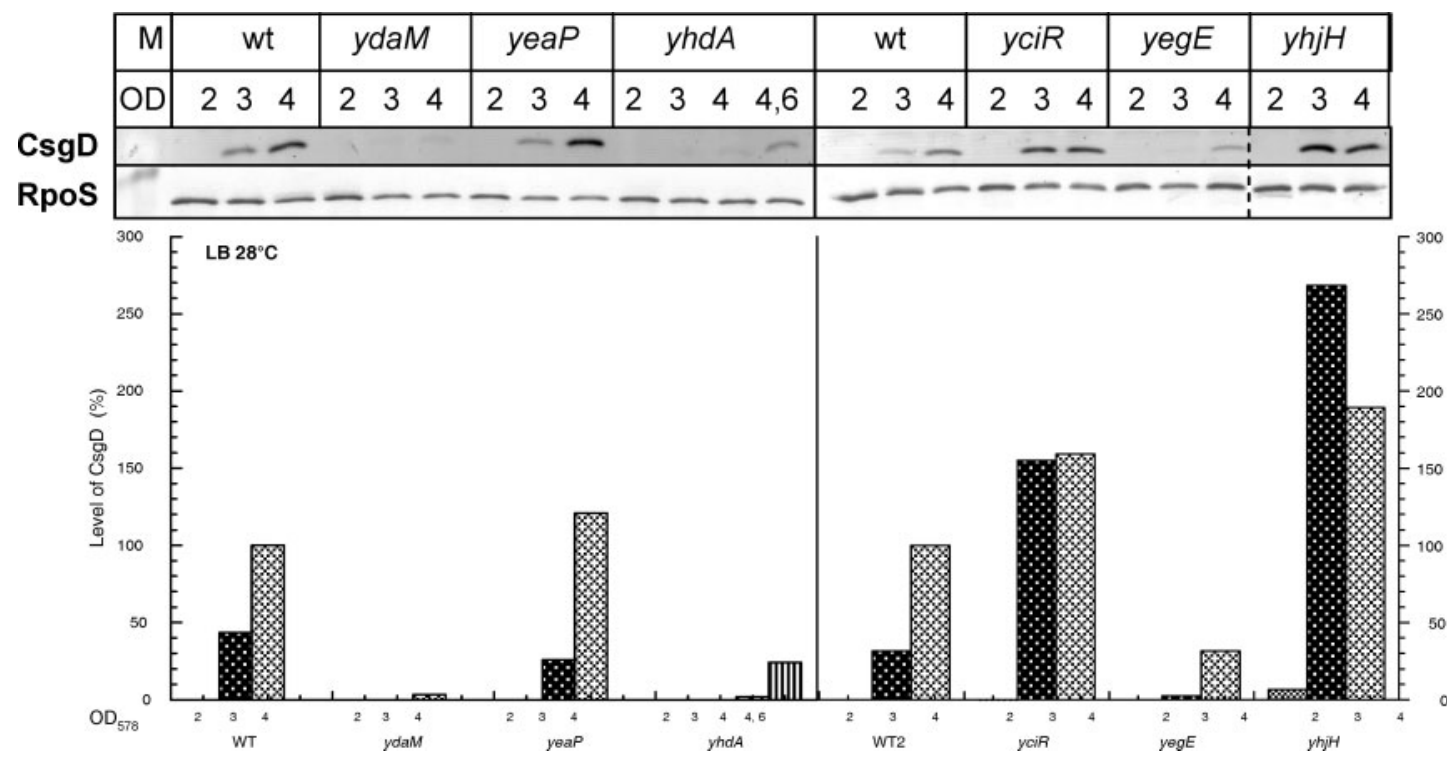

Fig. 4. Effects on CsgD protein levels of mutations that affect curli structural gene expression. W3110 derivatives carrying the mutations in GGDEF/EAL genes indicated were grown in LB at $28{ }^{\circ} \mathrm{C}$. At $\mathrm{OD}_{578} 2.0,3.0$ and 4.0, samples were taken for immunoblot analysis of $\sigma^{\mathrm{S}}$ and CsgD. Densitometric quantification of CsgD levels is shown below the blots. wt, Wild-type.

an EAL-only protein with PDE activity (Frye et al., 2006; Pesavento et al., 2008). These two proteins have been shown to antagonistically control motility in post-exponentially growing cells (at $37^{\circ} \mathrm{C}$; at $28{ }^{\circ} \mathrm{C}$, two other putative DGCs, YegE and YedQ, substitute for YeaJ; Pesavento et al., 2008). When cells enter into stationary phase, additional GGDEF/EAL proteins are induced, i.e. the c-di-GMP control potential represented by these proteins becomes more diverse.

Consistent with these growth phase-related expression patterns, we observed regulation by $\sigma^{\mathrm{S}}$ to be much more widespread among the 28 GGDEF/EAL domain-encoding genes in $E$. coli than was previously apparent when only a subset of these genes was analysed (Weber et al., 2006). Ten out of 21 expressed genes were positively $\sigma^{\mathrm{S}}$-controlled and clearly stationary phase-induced. Five of the corresponding proteins have GGDEF domains with intact A- and I-site motifs, and therefore (most likely) have DGC activity (YaiC, YdaM, YddV, YedQ and YegE). The other five positively $\sigma^{\mathrm{S}}$-controlled genes encode EAL-proteins (YciR, YddU, YjcC, YlaB and YoaD) with signatures consistent with PDE activity. In addition, five genes encoding GGDEF/EAL proteins were observed to be under negative control of $\sigma^{\mathrm{S}}$. This negative control is most likely due to increased formation of vegetative or other alternative RNAP holoenzymes in the absence of competition by $\sigma^{\mathrm{S}}$ with the other sigma factors (Gruber \& Gross, 2003; Weber et al., 2005). Negative control by $\sigma^{\mathrm{S}}$ was most clear for $y d e H$ (encoding a GGDEF domain; Fig. 1a), but became more apparent also for four other genes when cells were grown on solid medium (Fig. 2). The products of the latter four genes are all EAL proteins (YfeA, Rtn, $\mathrm{YcgF}$ and $\mathrm{YhjH}$; with YfeA also carrying an additional degenerate GGDEF domain). Interestingly, $y d e H$ was inversely growth rateregulated in the absence of $\sigma^{\mathrm{S}}$, suggesting that it shows specific activation and a distinct function under some stress conditions that reduce growth but do not induce $\sigma^{\mathrm{S}}$.

In conclusion, these data reveal an interesting overall pattern: during transition into stationary phase, E. coli uses $\sigma^{\mathrm{S}}$ control to deploy a diverse battery of GGDEF/EAL proteins, i.e. proven or putative DGCs and PDEs, which are not expressed (or are expressed at lower levels) in rapidly growing cells. This means that an intricate control of c-diGMP production and degradation, and therefore also of various targets that are controlled by c-di-GMP, becomes more important when cells enter into stationary phase. However, this does not automatically imply that stationary phase cells will always have increased c-di-GMP levels (although a tendency towards higher c-di-GMP levels is suggested by the downregulation of several genes for EAL proteins by $\sigma^{\mathrm{S}}$ ). Whether c-di-GMP actually accumulates in stationary phase may very much depend on the actual conditions that are perceived by the sensory input domains of these enzymes. From what is known about stationary phase induction and the role of $\sigma^{\mathrm{s}}$, c-di-GMP and temperature in curli regulation in E. coli and Salmonella (see above), it is clear that c-di-GMP levels must increase during entry into stationary phase at $28{ }^{\circ} \mathrm{C}$. Nevertheless, it is intriguing that in parallel, $\sigma^{\mathrm{S}}$-dependent EAL proteins (YciR, YddU, YjcC, YlaB and YoaD) accumulate, which represents a clear potential to rapidly break down c-diGMP when cells are suddenly challenged with conditions under which massive curli production or other c-di-GMPstimulated functions could become counterproductive. 

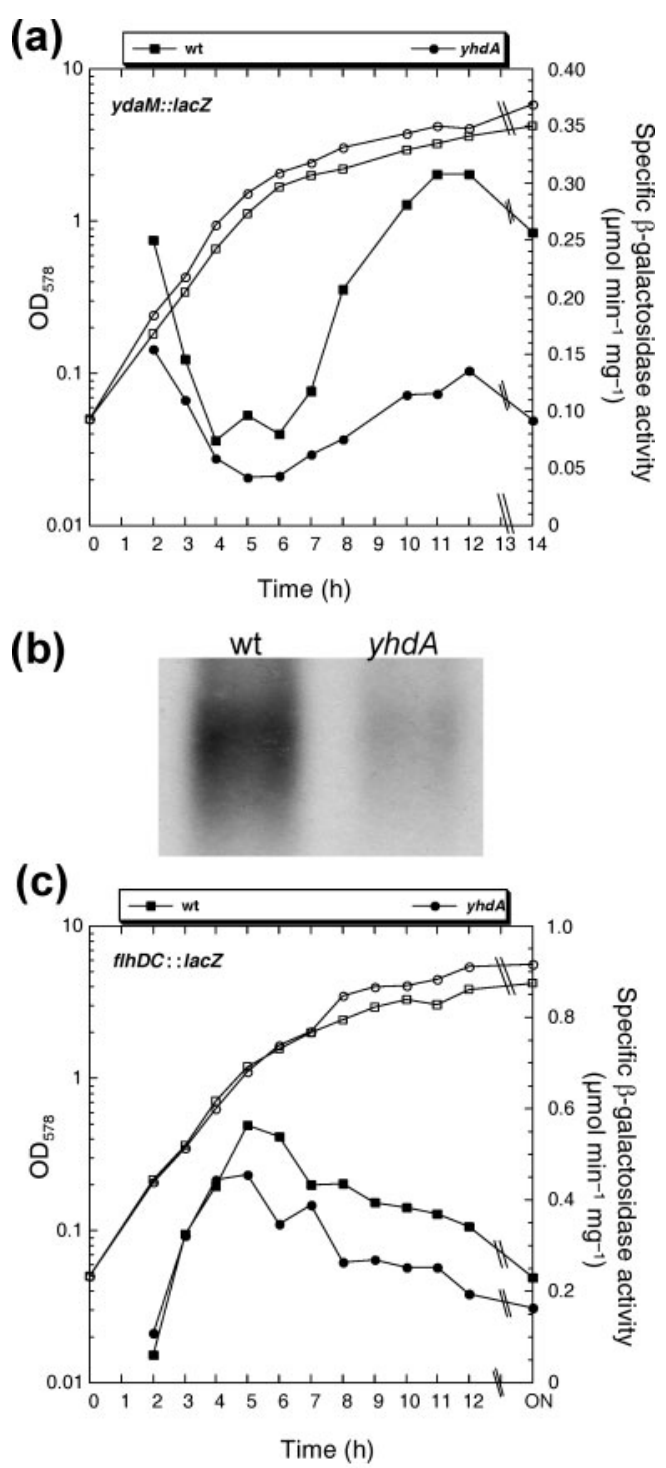

(d)

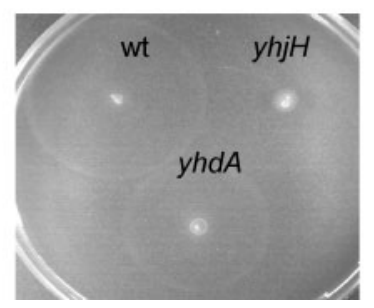

Fig. 5. The $y h d A$ mutation affects $y d a M$ expression, $\operatorname{csg} D$ mRNA levels, the expression of the flagellar master regulator FlhDC and motility. W3110 derivatives carrying the single-copy fusions ydaM : : lacZ (a, squares) or flhDC: : lacZ (c, squares), as well as the respective $y h d A$ knockout derivatives (circles in a and $c$ ) were grown in $\mathrm{LB}$ at $28{ }^{\circ} \mathrm{C}$, and $\mathrm{OD}_{578}$ (open symbols) and specific $\beta$-galactosidase activities (filled symbols) were determined along the growth curve. For the determination of $\operatorname{csg} D$ mRNA levels by Northern analysis (b), W3110 and its $y$ hdA derivative were grown in LB at $28{ }^{\circ} \mathrm{C}$ to $\mathrm{OD}_{578}$ 4.0. In (d), motility of W3110 and its $y h d A$ and $y h j H$ derivatives was assayed on swim plates. wt, Wild-type.
Another general pattern in the control of GGDEF/EAL domain-encoding genes is temperature regulation (Fig. 1, data summarized in Table 1). Of the 21 expressed genes, seven were increasingly or even exclusively expressed at reduced temperature $\left(28^{\circ} \mathrm{C} ; y a i C, y d a M, y d d V-y d d U\right.$, $y h j K, y c g F$ and $y o a D$ ). Only a single gene (yeaJ) showed somewhat higher expression at $37^{\circ} \mathrm{C}$, consistent with YeaJ being responsible for downregulation of motility at $37{ }^{\circ} \mathrm{C}$, but not at $28{ }^{\circ} \mathrm{C}$ (Pesavento et al., 2008). The tendency for increased expression below $37^{\circ} \mathrm{C}$ of many GGDEF/EAL proteins with diverse sensory input domains suggests that a multiple signal-integrating control of cellular c-di-GMP levels may be most important when E. coli finds itself in a highly variable environment outside the mammalian host.

Both $\sigma^{\mathrm{S}}$ control and temperature effects in the control of most GGDEF/EAL domain-encoding genes were even more pronounced when cells were grown on solid medium (in particular, negative regulation by $\sigma^{\mathrm{S}}$; compare data in Figs 1 and 2). In addition, a subset of four strongly $\sigma^{\mathrm{S}}$ dependent genes, ydaM, yciR, yaiC and yoaD, showed increased expression on solid medium in comparison with liquid medium. Precisely these four genes play important roles in the synthesis of curli fimbriae and cellulose (see below), i.e. they are determinants for the complex 'rdar' morphology of colonies on plates (Römling, 2005). Consistently, $\mathrm{YhjH}$, the PDE that maintains the low c-diGMP levels required for motility in liquid medium (Girgis et al., 2007; Ko \& Park, 2000; Pesavento et al., 2008; Ryjenkov et al., 2006; Simm et al., 2004), is downregulated on solid medium (Figs 1 and 2). Moreover, genes encoding GGDEF-only proteins ( $y a i C, y d a M, y d d V$ and yeaJ) clearly become dominantly expressed in cells growing on solid medium (Fig. 2), suggesting c-di-GMP accumulation under these conditions.

\section{Functions of a specific subset of GGDEF/EAL domain-encoding genes in the control of aggregative curli fimbriae}

A major target of positive c-di-GMP control is the synthesis of aggregative curli fimbriae (Römling et al., 2005). In E. coli, the DGC YdaM and the PDE YciR represent the c-di-GMP control module that specifically and apparently exclusively regulates the transcription of $\operatorname{csg} D$ (Weber et al., 2006), which encodes an activator that is essential for expressing the curli structural operon csgBAC. In addition, YegE and $\mathrm{YhjH}$ antagonistically modulate $\operatorname{csg} D$ transcription, and currently it is not clear how this influence is integrated with that of YdaM/YciR (Pesavento et al., 2008). CsgD also activates yaiC (agfD in Salmonella), which encodes the DGC that controls cellulose synthase activity (Römling et al., 2000; Simm et al., 2007). The relevant antagonist to YaiC may be the EAL protein YoaD, which shows a similar late timing of induction to that of YaiC (see Fig. 1b) and has been implicated in downregulating cellulose production (Brombacher et al., 2006). 
Here, we observed that two more genes encoding GGDEF/ EAL proteins, $y h d A$ and $y e a P$, are also involved in the regulation of curli expression in E. coli (Figs 3-5). YhdA plays a positive role in YdaM and CsgD expression during entry into stationary phase, which may reflect two separate effects that add up along the curli control cascade, as expression of CsgD seemed more strongly affected than YdaM expression. YhdA is unlikely to act via c-di-GMP, as both its GGDEF and its EAL domains are degenerate at amino acid positions crucial for DGC and PDE activities. In an earlier study (Suzuki et al., 2006), YhdA (there termed $\mathrm{CsrD}$ ) has been shown to stimulate the degradation of two small RNAs, CsrB and CsrC, which by sequestering the RNA-binding protein CsrA can downregulate the expression of the flagellar master regulator FlhDC at the post-transcriptional level. Consistent with these results, we found that YhdA is involved in the precise timing of the shutting-off of FlhDC expression during transition into stationary phase (Fig. 5c), which is required for curli induction (Pesavento et al., 2008). It seems unlikely that YhdA also acts via the Csr system in curli control, as ydaM and $\operatorname{csg} D$ were not among the genes affected by CsrA overproduction detected in a very recent microarray study (Jonas et al., 2008). Also, CsrA strongly interfered with the expression of two GGDEF domain-encoding genes $(y c d T$ and $y d e H$ ) (Jonas et al., 2008) that did not affect curli control (this study). Thus, curli regulation may involve some still unknown small regulatory RNA(s) targeted by YhdA.

In contrast to the mutations in $y d a M, y e g E$ and $y h d A$, knocking out yeaP (which encodes a known DGC; Ryjenkov et al., 2005) only partially reduced curli expression (Fig. 3a), and did not alter the expression of another $\mathrm{CsgD}$ target gene, yaiC (Fig. $3 \mathrm{~b}$ ). As the yeaP mutation also did not significantly affect CsgD expression (Fig. 4), YeaP seems to have a specific effect on curli fimbriae expression only. This effect may be linked with a specific requirement for $\mathrm{CsgD}$-stimulated transcription at the very strong $\operatorname{csg} B$ promoter by vegetative RNAP (Weber et al., 2006; the weakly active yaiC promoter is transcribed by $\sigma^{\mathrm{S}}$-containing RNAP; C. Pesavento and R. Hengge, unpublished data). Alternatively, YeaP may play a role in a post-transcriptional control of the csgBAC operon ( $\operatorname{csg} B:$ : lac $Z$ used here is a translational reporter fusion). While these mechanistic details have to be unravelled by future work, it is interesting to note that the DGC YeaP is already expressed in exponential phase (Fig. 1), but may have to be activated by unknown signals perceived by its GAF domain.

\section{What are the functions of GGDEF/EAL domain- encoding genes that are expressed but do not affect motility and/or the curli control pathway?}

Fourteen GGDEF/EAL genes were expressed to varying degrees in growing cells (Table 1), but only five were involved in motility control (yegE, yedQ, yeaJ, yhjH and
yhdA) (Girgis et al., 2007; Pesavento et al., 2008; Suzuki et al., 2006); 13 GGDEF/EAL genes continued to be expressed or were newly induced during entry into stationary phase, but only five played a role in curli control ( $y d a M, y c i R$, yegE, yhdA and yeaP; Pesavento et al., 2008; Weber et al., 2006; this study). What is the role of the other genes?

Two of these other genes ( $y c g F$ and $y d i V)$ encode EAL-only proteins with degenerate PDE signatures, i.e. these proteins most likely do not control c-di-GMP levels. The remaining genes could be activated at the genetic level, but the corresponding proteins may not be present due to posttranscriptional regulation or proteolysis. Alternatively, the proteins may be there but may be inactive in the absence of appropriate signals detected by their sensory input domains. Examples seem to be: (i) YeaJ, which plays a role in motility control at $37{ }^{\circ} \mathrm{C}$, but at $28{ }^{\circ} \mathrm{C}$, despite being expressed, affects neither motility nor curli formation (Pesavento et al., 2008); and (ii) YeaP, which is already expressed in exponential phase, but does not affect motility, and only later stimulates curli expression (Pesavento et al., 2008, and see above). Also, the influence of a GGDEF/EAL protein with relatively low expression may remain cryptic due to the functional redundancy of several such expressed proteins.

In addition, the multitude of GGDEF/EAL proteins in many species has led to the suggestion that these proteins are not only temporally sequestered (by means of differential control of expression and activity as discussed above), but also in a functional way, i.e. different GGDEF/ EAL systems present and active at the same time would operate in parallel in a locally separate manner. This involves a concept of 'microcompartimentation' and locally separate pools of c-di-GMP, which is supported by some evidence (Jenal \& Malone, 2006; Kader et al., 2006; Kulasakara et al., 2006; Pesavento et al., 2008; Ryan et al., 2006a; Weber et al., 2006). Ultimately, the question of c-diGMP control systems operating in parallel will have to be solved by demonstrating that the proteins involved (i) do have DGC/PDE activity, (ii) are expressed and (iii) affect clearly different targets under the same growth conditions. Our data about the expression and function of all GGDEF/ EAL domain-encoding genes in $E$. coli can indicate interesting candidates for such parallel-operating systems.

\section{A comparison of the functions of GGDEF/EAL proteins in the closely related $E$. coli and Salmonella}

The overall architecture of the curli control cascade is clearly the same in the closely related E. coli and Salmonella enterica (serovar Typhimurium) (Römling et al., 1998). However, c-di-GMP control in curli control seems rather different. Not only the numbers (29 or 28 versus 19) but also the identities of GGDEF/EAL proteins in the two species are surprisingly different (see Supplementary Table S2). In Salmonella, in which YdaM does not exist, STM3388 (a GGDEF + EAL protein not present in E. coli) 
and STM2133 (a YegE homologue) positively modulate CsgD expression, whereas the YciR homologue STM1703 and STM4264 (a homologue of the EAL-only protein YjcC) downregulate CsgD levels (Kader et al., 2006; Simm et al., 2007). In contrast to the situation in E. coli, YhjH seems to play a minor role in Salmonella: yhjH mutants show only partially reduced motility (Frye et al., 2006; Rychlik et al., 2002; Ryjenkov et al., 2006; Simm et al., 2007), and $\mathrm{YhjH}$ has a very minor effect if any on Salmonella curli expression (Simm et al., 2007). Thus, YjcC (STM4264) may be the major PDE for maintaining a low cellular c-diGMP pool in the post-exponential phase. In E. coli, however, YhjH plays this role: its knockout strongly reduces motility (Pesavento et al., 2008), YhjH (but not $\mathrm{YjcC}$ ) reduces the induction of $\mathrm{CsgD}$ and curli during entry into stationary phase (Figs 3 and 4 ), and yjcC expression is much lower than that of $y h j H$ and starts during entry into stationary phase only (Fig. 1). One may speculate that a simple variation in the promoters of $y j c C$ (to vary its $\sigma^{70} / \sigma^{\mathrm{S}}$ dependence) would suffice to generate these differences.

Also, the $y h d A$ gene is present in Salmonella. Although the effects on gene expression of a $y h d A$ mutation have not been studied in Salmonella, the mutation reduces cellular aggregation in liquid medium and results in a slight swimming defect (Simm et al., 2007), suggesting that it plays a similar role in controlling FlhDC and curli expression to that shown here for E. coli. Interestingly, the GGDEF protein YeaP, which specifically modulates the expression of the csgBAC curli operon in E. coli (Figs 3-5), does not exist in Salmonella. There is indirect evidence, however, that in Salmonella some unidentified c-di-GMP input also occurs downstream of the regulation of $\mathrm{CsgD}$ expression (Simm et al., 2007). In conclusion, a comparison of these two closely related bacterial species reveals that evolution can rapidly rewire conserved c-di-GMPcontrolled functions such as curli fimbriae expression to different signal inputs by horizontally acquiring and/or altering expression levels of genes encoding GGDEF/EAL domain proteins.

\section{ACKNOWLEDGEMENTS}

Financial support was provided by the Deutsche Forschungsgemeinschaft (He 1556/13-1), the Dr Hans-Messner-Stiftung and the Fonds der Chemischen Industrie.

\section{REFERENCES}

Adler, J. \& Templeton, B. (1967). The effect of environmental conditions on the motility of Escherichia coli. J Gen Microbiol 46, 175-184.

Amikam, D. \& Galperin, M. Y. (2006). PilZ domain is part of the bacterial c-di-GMP binding protein. Bioinformatics 22, 3-6.

Amsler, C. D., Cho, M. \& Matsumura, P. (1993). Multiple factors underlying the maximum motility of Escherichia coli as cultures enter post-exponential growth. J Bacteriol 175, 6238-6244.

Beloin, C., Roux, A. \& Ghigo, J.-M. (2008). Escherichia coli biofilms. Curr Top Microbiol Immunol 322, 249-289.
Benach, J., Swaminathan, S. S., Tamayo, R., Handelman, S. K., Folta-Stogniew, E., Ramos, J. E., Forouhar, F., Neely, H., Seetharaman, J. \& other authors (2007). The structural basis of cyclic diguanylate signal transduction by PilZ domains. EMBO J 26, 5153-5166.

Brombacher, E., Baratto, A., Dorel, C. \& Landini, P. (2006). Gene expression regulation by the curli activator $\mathrm{CsgD}$ protein: modulation of cellulose biosynthesis and control of negative determinants for microbial adhesion. J Bacteriol 188, 2027-2037.

Brown, P. K., Dozois, C. M., Nickerson, C. A., Zuppardo, A., Terlonge, J. \& Curtiss, R., III (2001). MlrA, a novel regulator of curli (Agf) and extracellular matrix synthesis by Escherichia coli and Salmonella enterica serovar Typhimurium. Mol Microbiol 41, 349-363.

Chang, A. L., Tuckerman, J. R., Gonzalez, G., Mayer, R., Weinhouse, H., Volman, G., Amikam, D., Benziman, M. \& Gilles-Gonzalez, M.-A. (2001). Phosphodiesterase Al, a regulator of cellulose synthesis in Acetobacter xylinum, is a heme-based sensor. Biochemistry 40, 3420-3426.

Christen, M., Christen, B., Folcher, M., Schauerte, A. \& Jenal, U. (2005). Identification and characterization of a cyclic di-GMP-specific phosphodiesterase and its allosteric control by GTP. J Biol Chem 280, 30829-30837.

Christen, M., Christen, B., Allan, M. G., Folcher, M., Jenö, P., Grzesiek, S. \& Jenal, U. (2007). DgrA is a member of a new family of cyclic diguanosine monophosphate receptors and controls flagellar motor function in Caulobacter crescentus. Proc Natl Acad Sci U S A 104, 4112-4117.

Datsenko, K. A. \& Wanner, B. L. (2000). One-step inactivation of chromosomal genes in Escherichia coli K-12 using PCR products. Proc Natl Acad Sci U S A 97, 6640-6645.

Frye, J., Karlinsey, J. E., Felise, H. R., Marzolf, B., Dowidar, N., McClelland, M. \& Hughes, K. T. (2006). Identification of new flagellar genes of Salmonella enterica serovar Typhimurium. J Bacteriol 188, 2233-2243.

Gerstel, U., Park, C. \& Römling, U. (2003). Complex regulation of $\operatorname{csg} D$ promoter activity by global regulatory proteins. Mol Microbiol 49, 639-654.

Girgis, H. S., Liu, Y., Ryu, W. S. \& Tavazoie, S. (2007). A comprehensive genetic characterization of bacterial motility. PLoS Genet 3, e154.

Gruber, T. M. \& Gross, C. A. (2003). Multiple sigma subunits and the partitioning of bacterial transcription space. Annu Rev Microbiol 57, 441-466.

Hayashi, K., Morooka, N., Yamamoto, Y., Fujita, K., Isono, K., Choi, S., Ohtsubo, E., Baba, T., Wanner, B. L. \& other authors (2006). Highly accurate genome sequences of Escherichia coli K-12 strains MG1655 and W3110 Mol Syst Biol 2, 2006.0007.

Hickman, J. W. \& Harwood, C. S. (2008). Identification of FleQ from Pseudomonas aeruginosa as a c-di-GMP-responsive transcription factor. Mol Microbiol 69, 376-389.

Hickman, J. W., Tifrea, D. F. \& Harwood, C. S. (2005). A chemosensory system that regulates biofilm formation through modulation of cyclic diguanylate levels. Proc Natl Acad Sci U S A 102, 14422-14427.

Jenal, U. \& Malone, J. (2006). Mechanisms of cyclic-di-GMP signaling in bacteria. Annu Rev Genet 40, 385-407.

Jonas, K., Edwards, A. N., Simm, R., Romeo, T., Römling, U. \& Melefors, O. (2008). The RNA binding protein CsrA controls c-diGMP metabolism by directly regulating the expression of GGDEF proteins. Mol Microbiol 70, 236-257.

Kader, A., Simm, R., Gerstel, U., Morr, M. \& Römling, U. (2006). Hierarchical involvement of various GGDEF domain proteins in rdar morphotype development of Salmonella enterica serovar Typhimurium. Mol Microbiol 60, 602-616. 
Ko, M. \& Park, C. (2000). Two novel flagellar components and H-NS are involved in the motor function of Escherichia coli. J Mol Biol 303, 371-382.

Kulasakara, H., Lee, E., Brencic, A., Liberati, N., Urbach, J., Miyata, S., Lee, D. G., Neely, A. N., Hyodo, M. \& other authors (2006). Analysis of Pseudomonas aeruginosa diguanylate cyclases and phosphodiesterase reveals a role for bis- $\left(3^{\prime}-5^{\prime}\right)$-cyclic-GMP in virulence. Proc Natl Acad Sci U S A 103, 2839-2844.

Lange, R. \& Hengge-Aronis, R. (1991). Identification of a central regulator of stationary-phase gene expression in Escherichia coli. Mol Microbiol 5, 49-59.

Lange, R. \& Hengge-Aronis, R. (1994). The cellular concentration of the $\sigma^{\mathrm{S}}$ subunit of RNA-polymerase in Escherichia coli is controlled at the levels of transcription, translation and protein stability. Genes Dev 8, 1600-1612.

Lee, V. T., Matewish, J. M., Kessler, J. L., Hyodo, M., Hayakawa, Y. \& Lory, S. (2007). A cyclic-di-GMP receptor required for bacterial exopolysaccharide production. Mol Microbiol 65, 1474-1484.

Malone, J. G., Williams, R., Christen, M., Jenal, U., Spiers, A. J. \& Rainey, P. B. (2007). The structure-function relationship of WspR, a Pseudomonas fluorescens response regulator with a GGDEF output domain. Microbiology 153, 980-994.

Méndez-Ortiz, M. M., Hyodo, M., Hayakawa, Y. \& MembrilloHernández, J. (2006). Genome wide transcription profile of Escherichia coli in response to high levels of the second messenger c-diGMP. J Biol Chem 281, 8090-8099.

Merighi, M., Lee, V. T., Hyodo, M., Hayakawa, Y. \& Lory, S. (2007). The second messenger bis-( $\left.3^{\prime}-5^{\prime}\right)$-cyclic-GMP and its PilZ domaincontaining receptor Alg44 are required for alginate biosynthesis in Pseudomonas aeruginosa. Mol Microbiol 65, 876-895.

Miller, J. H. (1972). Experiments in Molecular Genetics. Cold Spring Harbor, NY: Cold Spring Harbor Laboratory.

Olsén, A., Jonsson, A. \& Normark, S. (1989). Fibronectin binding mediated by a novel class of surface organelles on Escherichia coli. Nature 338, 652-655.

Paul, R., Weiser, S., Amiot, N., Chan, C., Schirmer, T., Giese, B. \& Jenal, U. (2004). Cell cycle-dependent dynamic localization of a bacterial response regulator with a novel di-guanylate cyclase output domain. Genes Dev 18, 715-727.

Pesavento, C., Becker, G., Sommerfeldt, N., Possling, A., Tschowri, N., Mehlis, A. \& Hengge, R. (2008). Inverse regulatory coordination of motility and curli-mediated adhesion in Escherichia coli. Genes Dev 22, 2434-2446.

Powell, B. S., Court, D. L., Nakamura, Y., Rivas, M. P. \& Turnbough, C. L., Jr (1994). Rapid confirmation of single copy lambda prophage integration by PCR. Nucleic Acids Res 22, 5765-5766.

Rao, F., Yang, Y., Qi, Y. \& Liang, Z. X. (2008). Catalytic mechanism of c-diGMP specific phosphodiesterase: a study of the EAL domain-containing RocR from Pseudomonas aeruginosa. J Bacteriol 190, 3622-3631.

Römling, U. (2005). Characterization of the rdar morphotype, a multicellular behaviour in Enterobacteriaceae. Cell Mol Life Sci 62, 1234-1246.

Römling, U., Bian, Z., Hammar, M., Sierralta, W. D. \& Normark, S. (1998). Curli fibers are highly conserved between Salmonella typhimurium and Escherichia coli with respect to operon structure and regulation. J Bacteriol 180, 722-731.

Römling, U., Rohde, M., Olsén, A., Normark, S. \& Reinköster, J. (2000). AgfD, the checkpoint of multicellular and aggregative behaviour in Salmonella typhimurium regulates at least two independent pathways. Mol Microbiol 36, 10-23.
Römling, U., Gomelsky, M. \& Galperin, M. Y. (2005). C-di-GMP: the dawning of a novel bacterial signalling system. Mol Microbiol 57, 629-639. Ryan, R. P., Fouhy, Y., Lucey, F. \& Dow, J. M. (2006a). Cyclic di-GMP signaling in bacteria: recent advances and new puzzles. J Bacteriol 188, 8327-8334.

Ryan, R. P., Fouhy, Y., Lucey, J. F., Crossman, L. C., Spiro, S., He, Y.-W., Zhang, L.-H., Heeb, S., Williams, P. \& Dow, J. M. (2006b). Cellcell signaling in Xanthomonas campestris involves an HD-GYP domain protein that functions in cyclic di-GMP turnover. Proc Natl Acad Sci U S A 103, 6712-6717.

Rychlik, I., Martin, G., Methner, U., Lovell, M., Cardova, L., Sebkova, A., Sevcik, M., Damborsky, J. \& Barrow, P. A. (2002). Identification of Salmonella enterica serovar Typhimurium genes associated with growth suppression in stationary-phase nutrient broth cultures and in the chicken intestine. Arch Microbiol 178, 411-420.

Ryjenkov, D. A., Tarutina, M., Moskvin, O. V. \& Gomelsky, M. (2005). Cyclic diguanylate is a ubiquitous signaling molecule in bacteria: insights into biochemistry of the GGDEF protein domain. J Bacteriol 187, 1792-1798.

Ryjenkov, D. A., Simm, R., Römling, U. \& Gomelsky, M. (2006). The PilZ domain is a receptor for the second messenger c-di-GMP: the PilZ protein YcgR controls motility in enterobacteria. J Biol Chem 281, 30310-30314.

Schmidt, A. J., Ryjenkov, D. A. \& Gomelsky, M. (2005). The ubiquitous protein domain EAL is a cyclic diguanylate-specific phosphodiesterase: enzymatically active and inactive EAL domains. $J$ Bacteriol 187, 4774-4781.

Simm, R., Morr, M., Kader, A., Nimtz, M. \& Römling, U. (2004). GGDEF and EAL domains inversely regulate cyclic di-GMP levels and transition from sessility to motility. Mol Microbiol 53, 1123-1134.

Simm, R., Lusch, A., Kader, A., Andersson, M. \& Römling, U. (2007). Role of EAL-containing proteins in multicellular behavior of Salmonella enterica serovar Typhimurium. J Bacteriol 189, 3613-3623.

Simons, R. W., Houman, F. \& Kleckner, N. (1987). Improved single and multicopy lac-based cloning vectors for protein and operon fusions. Gene 53, 85-96.

Sudarsan, N., Lee, E. R., Weinberg, Z., Moy, R. H., Kim, J. N., Link, K. H. \& Breaker, R. R. (2008). Riboswitches in eubacteria sense the second messenger cyclic di-GMP. Science 321, 411-413.

Suzuki, K., Babitzke, P., Kushner, S. R. \& Romeo, T. (2006). Identification of a novel regulatory protein (CsrD) that targets the global regulatory RNAs CsrB and CsrC for degradation by RNase E. Genes Dev 20, 2605-2617.

Tamayo, R., Tischler, A. D. \& Camilli, A. (2005). The EAL domain protein VieA is a cyclic diguanylate phosphodiesterase. J Biol Chem 280, 33324-33330.

Tamayo, R., Pratt, J. T. \& Camilli, A. (2007). Roles of cyclic diguanylate in the regulation of bacterial pathogenesis. Annu Rev Microbiol 61, 131-148.

Weber, H., Polen, T., Heuveling, J., Wendisch, V. \& Hengge, R. (2005). Genome-wide analysis of the general stress response network in Escherichia coli: $\sigma^{\mathrm{S}}$-dependent genes, promoters and sigma factor selectivity. J Bacteriol 187, 1591-1603.

Weber, H., Pesavento, C., Possling, A., Tischendorf, G. \& Hengge, R. (2006). Cyclic-di-GMP-mediated signaling within the $\sigma^{\mathrm{S}}$ network of Escherichia coli. Mol Microbiol 62, 1014-1034.

Wolfe, A. J. \& Visick, K. L. (2008). Get the message out: cyclic-di-GMP regulates multiple levels of flagellum-based motility. J Bacteriol 190, $463-475$.

Edited by: J. Green 